\title{
Algorytm doboru parametrów geometrycznych sprzęgla odsuwnego do układu napędowego lokomotywy
}

\begin{abstract}
W pracy przedstawiono algorytm doboru parametrów geometrycznych sprzęła typu Alsthom do układu napędowego lokomotywy. Celem analizy jest polepszenie właściwości dynamicznych sprzęła, poprzez zmniejszenie odksztatceń w przegubach oraz zmniejszenie sit bezwładności generowanych $w$ badanym mechanizmie. Przedstawiona metoda doboru parametrów może być stosowana do projektowania nowych ukladów napędowych przystosowanych do dużych prędkości.
\end{abstract}

\section{Wstęp}

Dobór parametrów geometrycznych i fizycznych sprzęgieł odsuwnych do układów napędowych polega na wyznaczeniu wartości zmiennych decyzyjnych, przy których wartość sformułowanej funkcji jest najmniejsza. W trakcie doboru parametrów sprzęieł zmieniane są parametry geometryczne, czyli długości i kąty elementów mechanizmu. Zmiany długości i kątów ograniczone są poprzez wymiary geometryczne elementów do których przymocowane są mechanizmy. Na zmienne decyzyjne zostają nałożone ograniczenia wynikające głownie $\mathrm{z}$ kształtu i wymiarów geometrycznych tych elementów lokomotywy do których mocowany jest mechanizm sprzęgieł. Ograniczenia wynikają z konstrukcji zestawu kołowego oraz wału drążonego. W niniejszej pracy przyjęto liniowy, przedziałowy zakres zmian parametrów. Funkcję celu przyjęto jako skorygowaną sumę ważoną dwóch kryteriów. Wprowadzono współczynniki wagowe, za pomocą których projektant przeprowadzający optymalizację ustala znaczenie poszczególnych kryteriów.

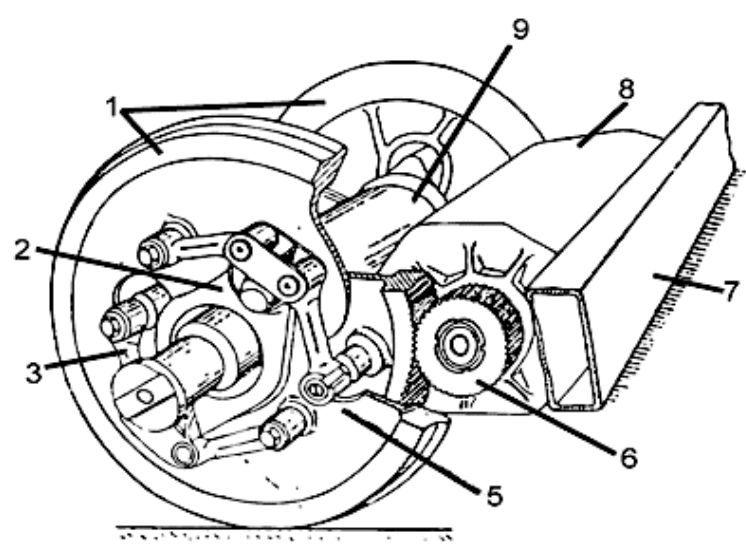

Rys. 1. Schemat układu napędowego stosowanego w pojazdach trakcyjnych

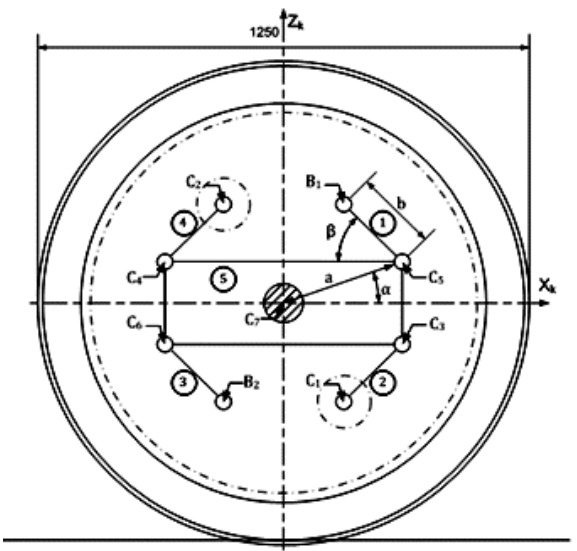

Rys. 2. Schemat sprzęłła przyjętego do analizy w układzie koła zestawu

\section{Podstawy teoretyczne}

Na rysunku 1 [3] przedstawiono poglądowy schemat konstrukcyjny układu napędowego ze sprzęgłami odsuwnymi typu Alsthom. Silnik trakcyjny 8 przymocowany jest do ramy 7 wózka lokomotywy. Na wale jego wirnika osadzone jest małe koło zębate 6 . Siły z czopów napędzających 5 osadzonych na dużym kole zębatym przekładni lub tarczy przenoszą się na cięgła 3. Zarówno koło zębate jak i tarcza osadzone są na końcach wału drążonego 9 . Z czopów 5 siły przenoszone są dalej na jarzmo 2, a $z$ niego ciegłami 4 na czopy wprasowane do kół napędnych 1 zestawu kołowego. Wał osiowy zestawu przechodzi przez wnętrze wału drążonego. Wymagany jest nie tylko dobór odpowiedniego typu sprzęgła kompensującego, uzależniony między innymi od rozwiązania konstrukcyjnego układu przeniesienia napędu, ale również optymalny dobór jego parametrów. Problemy mechaniki i optymalizacji wspomnianych sprzęgieł szeroko rozpatrzono w wielu pracach, przykładowo [3 i 4 ]. 
Rozważany mechanizm w położeniu konstrukcyjnym opisywany jest odpowiednimi parametrami wymiarowymi. Są nimi długości $a$ i $b$ oraz kąty $\alpha$ i $\beta$. Dla badanego mechanizmu parametr $a$ jest długością odcinka $\mathrm{C}_{07} \mathrm{C}_{05}$, a kąt $\alpha$ jest kątem nachylenia tych odcinków do poziomu, czyli osi $\mathrm{O}_{\mathrm{k}} \mathrm{X}_{\mathrm{k}}$. Odcinek $b$ jest długością każdego z czterech cięgieł nachylonych do poziomu pod katem $\beta$. Rozpatrywany mechanizm ma dwa stopnie ruchliwości. Zakładamy, że punkt $\mathrm{O}_{\mathrm{k}}$ przemieszcza się po osi $\mathrm{O}_{\mathrm{w}} Z_{\mathrm{w}}$, a kąt $\varphi=\varphi(t)$ jest kątem pomiędzy osiami $\mathrm{O}_{\mathrm{k}} Z_{\mathrm{k}}$ a $\mathrm{O}_{\mathrm{w}} Z_{\mathrm{w}}$ czyli kątem obrotu układu $\mathrm{O}_{\mathrm{k}} \mathrm{X}_{\mathrm{k}} Z_{\mathrm{k}}$ koła zestawu względem układu $\mathrm{O}_{\mathrm{w}} \mathrm{X}_{\mathrm{w}} Z_{\mathrm{w}}$ ramy wózka. Przyjmujemy, że wielkość $e(t)$ jest współrzędną punktu $\mathrm{O}_{\mathrm{k}}$ na osi $\mathrm{O}_{\mathrm{w}} Z_{\mathrm{w}}$. Wynika stąd, że $|e(t)|$ jest odległością łączonych wałów.

Zadanie doboru parametrów geometrycznych i fizycznych do układów napędowych sprzęgieł odsuwnych można najogólniej zapisać w następującej postaci

$$
\mathbf{x}_{\mathrm{opt}} \in \mathbf{X}_{0}=\left\{\mathbf{x}: g_{j}(x) \leq 0, j=1,2, \ldots, m\right\}
$$

gdzie:

$$
\begin{aligned}
& f_{\text {cel }}\left(\mathbf{x}_{\text {opt }}\right)=\min f_{\text {cel }}(x), \mathbf{x} \in \mathbf{X}_{0} \\
& \mathbf{X}_{0}-\text { zbiór rozwiązań dopuszczalnych, } \\
& \mathbf{x}-\text { wektor zmiennych decyzyjnych, } \\
& f_{\text {cel }}-\text { funkcja celu, } \\
& g_{j}-\text { funkcje ograniczeń. }
\end{aligned}
$$

Celem doboru parametrów mechanizmów jest uzyskanie takich parametrów konstrukcyjnych, aby uległy polepszeniu właściwości dynamiczne sprzęgieł. Polepszenie właściwości dynamicznych będzie polegało na zmniejszeniu odkształceń $\mathrm{w}$ przegubach, a także zmniejszeniu sił bezwładności generowanych w badanych mechanizmach i przenoszonych przez elementy oraz podzespoły układu napędowego. Dla obu mechanizmów przyjęto wstępnie określone parametry konstrukcyjne. Warunkiem dokonania doboru parametrów jest sprawny i skuteczny wybór: zmiennych decyzyjnych charakteryzujących dany problem, funkcji celu oraz zakresu zmian parametrów. Ponadto ważne jest wskazanie takiego sposobu doboru parametrów, przy którym uzyskamy satysfakcjonujące wyniki obliczeń w dostatecznie krótkim czasie.

W trakcie doboru parametrów sprzęgieł zmieniane są długości i kąty elementów mechanizmu. Zmiany długości i kątów ograniczone są poprzez wymiary geometryczne elementów do których przymocowane są mechanizmy. Elementami ograniczającymi są: wymiary koła zestawu kołowego oraz rozmieszczenie otworów w kole bosym. Wektor zmiennych decyzyjnych dla sprzęgła typu Alsthom można przedstawić następująco

$$
\mathbf{x}_{\mathrm{A}}=\left[\begin{array}{lll}
a & b & \alpha \beta
\end{array}\right]^{\mathrm{T}}
$$

Na zmienne decyzyjne zostają nałożone ograniczenia wynikające głównie z kształtu i wymiarów geometrycznych tych elementów lokomotywy do których mocowany jest mechanizm sprzęgieł. Ograniczenia wynikają z konstrukcji zestawu kołowego oraz wału drążonego. W niniejszej pracy przyjęto liniowy, przedziałowy zakres zmian parametrów. Zatem dla sprzęgła typu Alsthom przedstawionego na rysunku 2 ograniczenia nałożone na parametry są następujące

$$
\begin{aligned}
& a_{\min } \leq a \leq a_{\max } \\
& b_{\min } \leq b \leq b_{\max } \\
& \alpha_{\min } \leq \alpha \leq \alpha_{\max } \\
& \beta_{\min } \leq \beta \leq \beta_{\max }
\end{aligned}
$$

Sa to ograniczenia o charakterze liniowym. Wynikają one stąd, że poszczególne elementy mechanizmu muszą znajdować się w bezpiecznej odległości od koła zestawu kołowego. Celem przeprowadzanego doboru parametrów mechanizmów jest uzyskanie takich parametrów konstrukcyjnych, aby uległy polepszeniu właściwości dynamiczne sprzegieł. Należało zatem przyjąć odpowiednie wskaźniki, określające stan mechanizmu w zależności od przyjętych parametrów. Głównym celem doboru jest zmniejszenie odkształceń promieniowych $\mathrm{w}$ przegubach, a także zmniejszenie sił bezwładności generowanych w badanych mechanizmach. Należy więc stworzyć dwa kryteria, które pozwolą na ocenę działania mechanizmów. Jedną z metod równoczesnego uwzględnienia dwóch kryteriów jest użycie sumy ważonej. Pierwsze kryterium przyjmujemy jako kwadrat odchylenia standardowego zaburzeń odkształceń elementu podatnego w jednym wybranym przegubie

$$
f_{o}(x)=\frac{\stackrel{\circ}{\mathrm{a}}_{i=1}^{N_{o}}\left(u_{i}-u_{m}\right)^{2}}{N_{o}}
$$

gdzie:

$u_{i}$ - wartość odkształcenia w wybranym przegubie,

$u_{m}$ - średnia wartość odkształcenia promieniowego w wybranym przegubie,

$N_{\mathrm{o}}$ - liczba próbek przebiegu zmian odkształcenia.

Drugie kryterium przyjmujemy jako kwadrat odchylenia standardowego zaburzeń sił bezwładności generowanych w badanych mechanizmach

$$
f_{b}(x)=\frac{\stackrel{\circ}{\mathrm{a}}_{i=1}^{N_{b}}\left(f_{i}-f_{m}\right)^{2}}{N_{b}}
$$

gdzie:

$F_{i}$ - wartość siły bezwładności działającej na jarzmo mechanizmu,

$f_{m}$ - średnia wartość siły bezwładności,

$N_{b}$ - liczba próbek przebiegu zmian siły bezwładności. 
Funkcję celu przyjęto jako skorygowaną sumę ważoną tych dwóch kryteriów. Podczas tworzenia funkcji celu uwzględniono fakt, iż wpływ poszczególnych kryteriów na zachowanie się mechanizmu sprzęła nie jest jednakowy. Dlatego wprowadzono współczynniki wagowe, za pomocą których projektant przeprowadzający optymalizację ustala znaczenie poszczególnych kryteriów. Korzystne jest takie skonstruowanie funkcji celu, aby wpływ poszczególnych kryteriów był jednakowy, a zastosowane wagi powinny służyć głównie do określenia ważności poszczególnych kryteriów. Aby wpływ poszczególnych kryteriów był jednakowy, należy dokonać skalowania wartości przebiegów zmienności odkształcenia w wybranym przegubie oraz siły bezwładności działającej na jarzmo mechanizmu do przedziału $(0,1)$ korzystając $\mathrm{z}$ następującego wzoru ogólnego

$$
k(\mathbf{x})=\frac{K(x)-K_{\min }}{K_{\max }-K_{\min }}
$$

gdzie:

$K(x)$ - początkowe wartości przebiegu odkształcenia lub siły bezwładności,

$K_{\min }-$ minimalna wartość odkształcenia lub siły bezwładności,

$K_{\max }-$ maksymalna wartość odkształcenia lub siły bezwładności.

Zakładamy najpierw wartość pierwszego współczynnika wagowego równą jedności, a drugiego równą zeru. Następnie przeprowadzamy jednokryterialną optymalizację testującą ze względu na pierwsze kryterium. Określamy maksymalne i minimalne wartości zmian odkształcenia, po czym przeprowadzamy skalowanie przebiegu odkształcenia do przedziału $(0,1)$, dzięki czemu otrzymujemy nowy przebieg zmienności odkształcenia $f_{\text {os }}(\mathbf{x})$. Następnie przeprowadzamy analogiczne operacje dla drugiego kryterium i otrzymujemy przebieg $f_{\text {bs }}(\mathbf{x})$. Po przeskalowaniu przebiegów zmian odkształcenia oraz siły bezwładności, w zasadniczym doborze parametrów mechanizmu sprzęgieł można przyjmować współczynniki wagowe zgodnie $\mathrm{z}$ wymaganiami konstruktora. Ostatecznie funkcja celu przyjmuje następującą postać

$$
f_{\mathrm{cel}}(\mathbf{x})=w_{1} f_{\mathrm{os}}(\mathbf{x})+w_{2} f_{\mathrm{bs}}(\mathbf{x})
$$

gdzie:

$$
\begin{gathered}
w_{k}-\text { współczynniki wagowe, } k=1,2 . \\
w_{1}+w_{2}=1, w_{1} \geq 0, w_{2} \geq 0
\end{gathered}
$$

Ze względu, na fakt, że mechanizm każdego sprzęgła jest rozwiązywany numerycznie i nie jest znana analityczna postać rozwiązań równań opisujących ruch mechanizmu, funkcja celu również musi być każdorazowo obliczana. Oznacza to znaczne skomplikowanie i wydłużenie obliczeń.

\section{Obliczenia}

Najbardziej czasochłonnym etapem w trakcie doboru parametrów było numeryczne rozwiązanie układu równań opisujących kinematykę mechanizmu sprzęgła. Ponieważ dobór parametrów z wykorzystaniem standardowych metod optymalizacyjnych: zdeterminowanych jak i losowych, nie dawał satysfakcjonujących wyników, zdecydowano się na inny sposób doboru parametrów. Do analiz przyjmujemy mechanizm o parametrach geometrycznych i fizycznych przedstawionych $\mathrm{w}$ tabeli 1 . Wymiary elementów mechanizmu przyjęto z pracy [5], natomiast sztywności elementów metalowo-gumowych przyjęto z pomiarów wykonanych przez Centralne Biuro Konstrukcyjne Przemysłu Taboru Kolejowego z Poznania [6].

Współczynniki wagowe przyjmujemy w sposób następujący

$$
w_{1}=w_{2}=0,5
$$

Prędkość lokomotywy ustalona została na 120 $\mathrm{km} / \mathrm{h}$, a moment napędowy ustalono na $12 \mathrm{kNm}$. Wartość przyjętego momentu napędowego odpowiada lokomotywie EP09, w której pojedynczy silnik trakcyjny napędzający jeden zestaw kołowy ma moc 735 $\mathrm{kW}$. Często stosowane podejście do problemu rozwiązania zadania optymalizacji polega na obliczaniu wartości funkcji celu ze wzoru lub odpowiedniej procedury. W przypadku przedstawionej metody obliczanie wartości funkcji celu ze wzoru nie było możliwe, a obliczenia przy wykorzystaniu odpowiedniej procedury obliczeniowej byłyby bardzo czasochłonne. W związku z tym w pracy przyjęto centralny, kompozycyjny plan eksperymentu i na jego podstawie dokonano wyboru osiemdziesięciu dwóch kombinacji parametrów sprzęgła. Mechanizm został rozwiązany dla każdego zestawu parametrów.

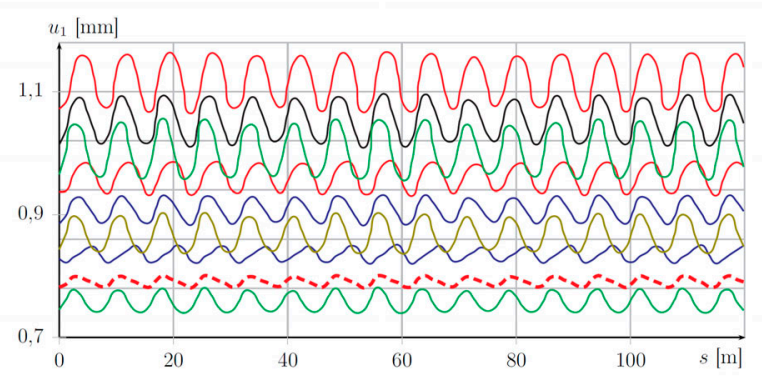

Rys. 4. Zmiana odkształcenia promieniowego przegubu $\mathrm{C}_{5}$ dla wybranych zestawów parametrów na drodze $120 \mathrm{~m}$ 


\begin{tabular}{|c|c|c|c|c|c|c|}
\hline$a[\mathrm{~m}]$ & $b[\mathrm{~m}]$ & $\alpha\left[^{\circ}\right]$ & $\beta\left[{ }^{\circ}\right]$ & $m_{j}[\mathrm{~kg}]$ & $c_{r}[\mathrm{kN} / \mathrm{mm}]$ & $c_{\varphi}[\mathrm{kNm} / \mathrm{rad}]$ \\
\hline 0,348 & 0,258 & 19 & 45 & 50 & 31,4 & 2,89 \\
\hline
\end{tabular}

gdzie:

$$
\begin{aligned}
& a, b, \alpha, \beta-\text { parametry geometryczne sprzegla } \\
& m_{j}-\text { masa jarzma } \\
& c_{r}, c_{\varphi}-\text { stałe sprężystości elementów metalowo - gumowych }
\end{aligned}
$$

Przyjmujemy również, że parametry geometryczne sprzęgła będą się zmieniały następująco:

\section{Zakresy zmian (Min, Max) i zastosowane wartości parametrów (Nom) \\ Tabela 2} sprzęgla typu Alsthom

\begin{tabular}{|c|c|c|c|}
\hline Parametry Alsthom & Min & Nom & Max \\
\hline$a[\mathrm{~m}]$ & 0,313 & 0,348 & 0,383 \\
\hline$b[\mathrm{~m}]$ & 0,232 & 0,258 & 0,284 \\
\hline$\alpha\left[^{\circ}\right]$ & 17 & 19 & 21 \\
\hline$\beta\left[^{\circ}\right]$ & 40 & 45 & 50 \\
\hline
\end{tabular}

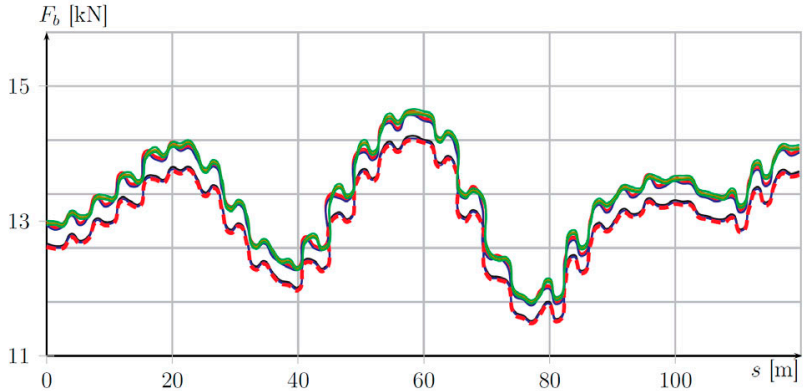

Rys. 5. Zmiana siły bezwładności działającej na jarzmo dla wybranych zestawów parametrów na drodze $120 \mathrm{~m}$

Na podstawie zapisanych wyników obliczeń wygenerowano wykresy przebiegów zmian odkształceń $u_{1}$ elementu gumowego $\mathrm{w}$ przegubie $\mathrm{C}_{5}$ oraz zmian siły bezwładności $F_{\mathrm{b}}$ działającej na jarzmo mechanizmu. Wspomniane przebiegi przedstawiono na rysunkach 4 i 5.

$\mathrm{Na}$ wykresach pogrubiona, przerywaną linią zaznaczono przebiegi, które odpowiadają najmniejszej wartości funkcji celu przy założonych danych i ograniczeniach. W tabeli 3 zamieszczono parametry konstrukcyjne mechanizmu oraz najlepszy zestaw parametrów otrzymany $\mathrm{w}$ wyniku rozwiązania mechanizmu z wykorzystaniem założonego planu eksperymentu.
Aby sprawdzić czy otrzymane rozwiązanie jest dla danego mechanizmu najlepsze stworzono funkcję regresji w postaci:

$$
\begin{gathered}
f_{\text {reg }}(a, b, \alpha, \beta)=r_{1}+r_{2} a+r_{3} b+r_{4} \alpha+r_{5} \beta+r_{6} a b+r_{7} \alpha \beta+r_{8} a \alpha \\
+r_{9} a+r_{10} b \alpha+r_{11} b \beta+r_{12} a^{2}+r_{13} b^{2}+r_{14} \alpha^{2}+r_{15} \beta^{2}
\end{gathered}
$$

Wykorzystując osiemdziesiąt dwa zestawy parametrów $a, b, \alpha, \beta$ i wartości funkcji celu dla nich obliczonych dobrano stałe funkcji regresji $r_{1}$ do $r_{15}$. Wartości parametrów podano $\mathrm{w}$ tabeli 4 :

Otrzymaną funkcję regresji podajemy minimalizacji wykorzystując do tego algorytm ewolucji różnicowej. Po niewielkim zaokragleniu wyników otrzymujemy następujące wartości:

\begin{tabular}{|c|c|c|c|}
\hline$a[\mathrm{~m}]$ & $b[\mathrm{~m}]$ & $\alpha\left[^{\circ}\right]$ & $\beta\left[^{\circ}\right]$ \\
\hline 0,383 & 0,232 & 21 & 45 \\
\hline
\end{tabular}

Otrzymane tym sposobem wyniki nie różnią się od wyników otrzymanych przy wykorzystaniu metod planowania eksperymentu. Na poniższych wykresach przedstawiono natomiast zmianę odkształcenia elementu gumowego oraz siły bezwładności dla parametrów konstrukcyjnych sprzęgła oraz dla najlepszego uzyskanego zestawu parametrów.

Wynik doboru parametrów sprzęgła typu Alsthom

Tabela 3

\begin{tabular}{|c|c|c|c|c|}
\hline & $\mathrm{a}[\mathrm{m}]$ & $\mathrm{b}[\mathrm{m}]$ & $\alpha\left[^{\circ}\right]$ & $\beta\left[^{\circ}\right]$ \\
\hline Parametry początkowe & 0,348 & 0,258 & 19 & 45 \\
\hline Parametry otrzymane & 0,383 & 0,232 & 21 & 45 \\
\hline Zmiana & $9 \%$ & $-11 \%$ & $9 \%$ & $0 \%$ \\
\hline
\end{tabular}

Stałe funkcji regresji

Tabela 4

\begin{tabular}{|c|c|c|c|c|c|}
\hline r1 & 0,2471 & r6 & $-0,2519$ & r11 & $-0,0256$ \\
\hline r2 & $-0,2625$ & r7 & 0,0402 & r12 & 0,3121 \\
\hline r3 & 0,1582 & r8 & 0,0926 & r13 & $-0,0357$ \\
\hline r4 & $-0,0702$ & r9 & 0,0612 & r14 & 0,0153 \\
\hline r5 & $-0,4644$ & r10 & $-0,0371$ & r15 & 0,2760 \\
\hline
\end{tabular}




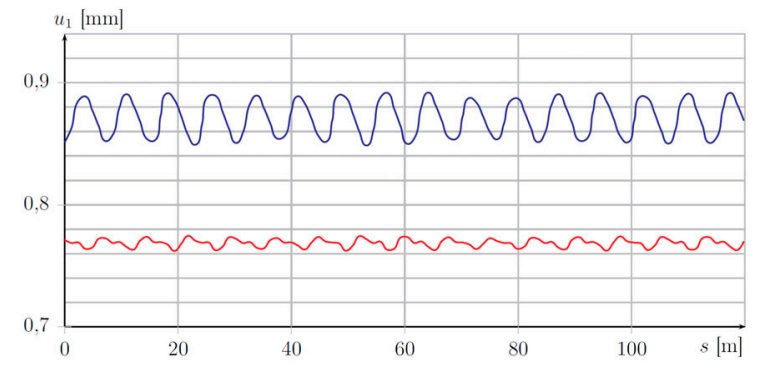

Rys. 6. Zmiana odkształcenia promieniowego przegubu $\mathrm{C}_{5}$ na drodze $120 \mathrm{~m}$ dla parametrów wyjściowych oraz najlepszego otrzymanego zestawu parametrów

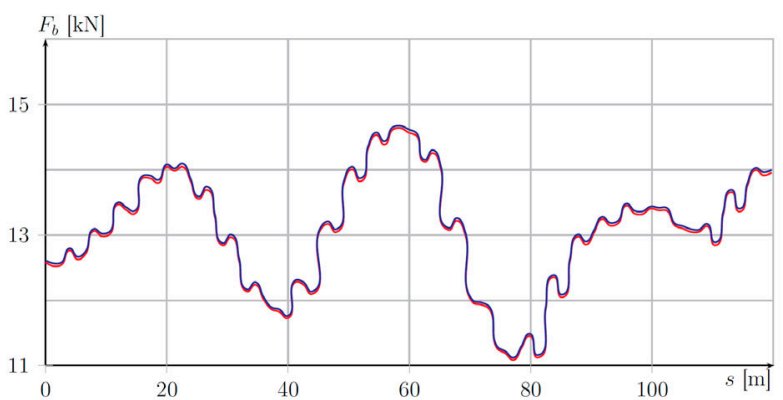

Rys. 7. Zmiana siły bezwładności działającej na jarzmo dla parametrów wyjściowych oraz najlepszego otrzymanego zestawu parametrów

Wartości zmian siły bezwładności jarzma oraz odkształceń $\mathrm{W}$ przegubie określonym wektorem $\mathrm{p}_{1} \mathrm{C}_{5}$ przedstawione zostały w tabeli 5 (znak minus oznacza zmniejszenie wartości danej wielkości po doborze parametrów).

Tabela 5

Zestawienie wyników dotyczących odkształceń w przegubie określonym wektorem $p_{1} C_{5}$ oraz sily bezwładności dzialającej na jarzmo dla sprzęgla typu Alsthom

\begin{tabular}{|c|c|c|}
\hline \multicolumn{3}{|c|}{$\begin{array}{c}\text { Odkształcenie w przegubie określonym } \\
\text { wektorem } \mathbf{p}_{\mathbf{1}} \mathbf{C}_{\mathbf{5}}\end{array}$} \\
\cline { 1 - 2 } $\begin{array}{c}\text { Przed doborem } \\
\text { parametrów }\end{array}$ & $\begin{array}{c}\text { Po doborze } \\
\text { parametrów }\end{array}$ & $\begin{array}{c}\text { Zmiana } \\
{[\%]}\end{array}$ \\
\hline Średnia [m] & Średnia [m] & \\
\hline 0,000863 & 0,000771 & $-11,84$ \\
\hline \multicolumn{3}{|c|}{ Siła bezwładności działająca na jarzmo } \\
\cline { 1 - 2 } \begin{tabular}{c|c|c} 
Przed doborem \\
parametrów
\end{tabular} & $\begin{array}{c}\text { Po doborze } \\
\text { parametrów }\end{array}$ & $\begin{array}{c}\text { Zmiana } \\
{[\%]}\end{array}$ \\
\hline Srednia $[\mathrm{kN}]$ & Srednia $[\mathrm{kN}]$ & \\
\hline 13,02 & 12,98 & $-0,28$ \\
\hline \multicolumn{3}{|c}{} \\
\hline
\end{tabular}

Podsumowując, zmiana wartości parametrów zgodnie z tabelą 5 , przy założonych ograniczeniach pozwoliła na zmniejszenie średnich odkształceń w wybranym przegubie o około $12 \%$. Siła bezwładności działająca na jarzmo zmalała o około $0,3 \%$ zarówno w przypadku średniej jak i odchylenia standardowego.

\section{Literatura}

[1] Grzyb A., Symulacja komputerowa ruchu mechanizmów sprzęgiet odsuwnych, I Konferencja Nowe Technologie $w$ nauczaniu na odległość, Koszalin-Osieki, 2005.

[2] Madej J., Projektowanie mechanizmów napędowych pojazdów szynowych, WKt, Warszawa 1988.

[3] Os i e cki J., Equations of vibrations and analisis of the dynamics loadings of a drive system with Alsthomtype couplings, Nonlin. Vibr. Problems, 10, 1969, s. 225-243.

[4] Życzkowski M., Romaniszyn Z., Optymalizacja kinematyczna mechanizmu cięgłowego typu Alsthom, Archiwum Budowy Maszyn, Tom XVI, Kraków 1969.

[5] Sachs K.,Elektrische Triebfahrzeuge, SpringerVerlag,Wien, 1973.

[6] Centralne Biuro Konstrukcyjne Przemystu Taboru Kolejowego, Tulejka metalowo-gumowa, Rys. $n r$ 4E091601-1-0, Poznań, 2007. 